\title{
Application of DPC and DPC-GA to the dual-rotor wind turbine system with DFIG
}

\author{
Habib Benbouhenni \\ Department of Electrical Engineering, Lab. LAAS, National Polytechnic of Oran, Algeria
}

\begin{tabular}{|c|c|}
\hline Article Info & ABSTRACT \\
\hline Article history: & The work presents the dual-rotor wind energy conversion system (DRWECS) \\
\hline Received Jan 29, 2021 & $\begin{array}{l}\text { with a direct driven doubly-fed induction generator (DFIG). The system } \\
\text { consists of a dual-rotor wind turbine (DRWT) with a DFIG, the grid side }\end{array}$ \\
\hline Revised Apr 9, 2021 & converter (GSC), and the machine side converter (MSC). To command the \\
\hline Accepted Apr 14, 2021 & $\begin{array}{l}\text { MSC, the direct power command (DPC) based on genetic algorithm (GA) } \\
\text { and classical pulse width modulation (PWM) has been applied. To achieve }\end{array}$ \\
\hline Keywords: & $\begin{array}{l}\text { the maximum power from the DRWT, the maximum power point tracking } \\
\text { (MPPT) technique has been used. The performed simulation studies } \\
\text { confirmed the high performances of the DPC-GA control method. }\end{array}$ \\
\hline
\end{tabular}

This is an open access article under the $\underline{C C B Y-S A}$ license.

Dual-rotor wind turbine

MPPT

PWM

\begin{abstract}
The work presents the dual-rotor wind energy conversion system (DRWECS) with a direct driven doubly-fed induction generator (DFIG). The system consists of a dual-rotor wind turbine (DRWT) with a DFIG, the grid side and classical pulse width modulation (PWM) has been applied. To achieve the maximum power from the DRWT, the maximum power point tracking confirmed the high performances of the DPC-GA control method.
\end{abstract}

Doubly-fed induction generator

Dual-rotor wind energy

conversion system

\section{Corresponding Author:}

Habib Benbouhenni

Department of Electrical Engineering

Lab. LAAS

National Polytechnic of Oran

BP 1523 El M'naouerEs-Sénia, Oran, Algeria

Email: habib0264@gmail.com

\section{INTRODUCTION}

In the field of electrical energy, there are many different and varied sources, where we find renewable and non-renewable sources. Wind energy is a type of renewable energy. The latter has become the main pillar of the global economy and the production of electrical energy from the wind energy we use wind turbines. Currently, there are two types of turbines to generate electric power, which are single-rotor wind turbine (SRWT) and dual-rotor wind power (DRWP). But, the SRWT is widely used in electric power generation compared to DRWT and this is due to that DRWT is a newly discovered compared to the SRWT system. Also, the generation of electrical energy depends on converting mechanical energy into electrical energy, using generators, as there are several generators, for exemple: synchronous generator (SG), permanent magnet synchronous generator (PMSG), and doubly-fed induction generator (DFIG). In our article, we will rely on generating electric energy using a DFIG-based DRWT system. In the field of scientific resarche, there are several methods for controlling generators, for example: indirect vector control (IVC) [1]-[3], backstepping command [4]-[6], direct torque command (DTC) [7]-[10], direct vector command [11]-[13], direct power command (DPC) [14]-[18], intelligent command [19]-[22], non-linear command [23]-[25] and hybrid command [26]-[30].

In this work, the DPC technique with the application of the genetic algorithm (GA) and traditional PWM technique has been considered. The original contribution of this work is the application of the GA method in the DPC system with three-phase DFIG-based DRWT and simulation investigation of this new command strategy. 
This work is divided into seven parts. In section 1 , the introduction is presented. In section 2 , the model of the DFIG is described. The DRWT has been discussed in section 3. In section 4, the description of the classical DPC technique is presented. Section 5 deals with the description of the DPC technique with the application of a genetic algorithm. Simulation studies are presented and discussed in section 6 . We finished the paper with the conclusion.

\section{DFIG MODEL}

The mathematical model of the DFIG has been presented in detail in [31]-[33] by using the Park model. The equation of flux and voltages of rotor and stator DFIG are given as (1).

$$
\left\{\begin{array}{l}
V_{\mathrm{ds}}=R_{s} I_{\mathrm{ds}}+\frac{d}{\mathrm{dt}} \psi_{\mathrm{ds}}-\omega_{s} \psi_{\mathrm{qs}} \\
V_{\mathrm{qs}}=R_{s} I_{\mathrm{qs}}+\frac{d}{\mathrm{dt}} \psi_{\mathrm{qs}}+\omega_{s} \psi_{\mathrm{ds}} \\
V_{\mathrm{dr}}=R_{r} I_{\mathrm{dr}}+\frac{d}{\mathrm{dt}} \psi_{\mathrm{dr}}-\omega_{r} \psi_{\mathrm{qr}} \\
V_{\mathrm{qr}}=R_{r} I_{\mathrm{qr}}+\frac{d}{\mathrm{dt}} \psi_{\mathrm{qr}}+\omega_{r} \psi_{\mathrm{dr}}
\end{array}\right.
$$

The flux can be expressed as (2).

$$
\left\{\begin{array}{l}
\psi_{d s}=M I_{d r}+L_{s} I_{d s} \\
\psi_{q s}=M I_{q r}+L_{s} I_{q s} \\
\psi_{d r}=L_{r} I_{d r}+M I_{d s} \\
\psi_{q r}=L_{r} I_{q r}+M I_{q s}
\end{array}\right.
$$

The reactive and active powers can be expressed as (3).

$$
\left\{\begin{array}{l}
P_{s}=\frac{3}{2}\left(V_{d s} I_{d s}+V_{q s} I_{q s}\right) \\
Q_{s}=\frac{3}{2}\left(V_{q s} I_{d s}-V_{d s} I_{q s}\right)
\end{array}\right.
$$

The torque is expressed as (4).

$$
T_{e}=T_{r}+J \cdot \frac{d \Omega}{d t}+f \cdot \Omega
$$

\section{DUAL-ROTOR WIND TURBINE}

Traditionally, SRWT is a classical type of wind turbine used to this day in the production of electrical energy. The ideal maximum power coefficient of this type is 59\%. So, the SRWT gives us a somewhart average coefficient. There is another type of wind turbine that gives a larger coefficient called DRWT. The latter has a coefficient estimated at $64 \%$. Therefore, the DRWT improves the maximum power coefficient of 5\% compared to SRWT [34]. It can be said that DRWT gives us more torque and mechanical power than SRWT.

In the DRWT type, there are two turbines (Auxiliary turbine and main turbine). The block diagram of the DRWT show in Figure 1 [35]. The total aerodynamic torque of DRWT is the Auxiliary turbine plus the main turbine torque as shown by (5).

$$
T_{D R W T}=T_{T}=T_{M}+T_{A}
$$

Where: $\mathrm{T}_{\mathrm{M}}$ : Main turbine torque.

$\mathrm{T}_{\mathrm{A}}$ : Auxiliary turbine torque.

$\mathrm{T}_{\mathrm{T}}$ : Total torque or DRWT torque.

The aerodynamic torque of the auxiliary turbine are given by (6) [36].

$$
T_{A}=\frac{1}{2 \lambda_{A}^{3}} \cdot A \cdot \rho \cdot \pi \cdot R_{A}^{5} \cdot C_{P} \cdot w_{A}^{2}
$$

The aerodynamic torque of the main turbine are given by (7). 


$$
T_{M}=\frac{1}{2 \lambda_{M}^{3}} \cdot A \cdot \rho \cdot \pi \cdot R_{A}^{5} \cdot C_{P} \cdot w_{M}^{2}
$$

With Ra, RM: blade radius of the main and auxiliary turbines, $\lambda_{\mathrm{A}}, \lambda_{\mathrm{M}}$ : the tip speed ration of the main and auxiliary turbines, $\rho$ : the air density and $\mathrm{w}_{\mathrm{M}}, \mathrm{w}_{\mathrm{A}}$ the mechanical speed of the main and auxiliary rotors. Cp can be calculated as (8).

$$
C_{p}(\lambda, \beta)=\frac{1}{\lambda+0.08 \beta}-\frac{0.035}{\beta^{3}+1}
$$

With $\beta$ is pitch angle respectively.

The tip speed ratios for the main and auxiliary turbines are calculated through (9) and (10),

$$
\begin{aligned}
& \lambda_{A}=\frac{w_{A} \cdot R_{A}}{V_{1}} \\
& \lambda_{M}=\frac{w_{M} \cdot R_{M}}{V_{M}}
\end{aligned}
$$

Where $V_{1}$ is the wind speed on an AWT and $V_{M}$ is the speed of the unified wind on the main turbine. On the other hand, the essential element for calculating the tip speed ratio is wind speed on the main and auxiliary turbines. Obtaining the wind speed on the auxiliary turbine is straightforward. However, the calculation of wind speed on the main turbine requires further investigation. Based on (11), it is possible to estimate the amount of the wind speed at any point between the auxiliary and main blades.

$$
V_{x}=V_{1}\left(1-\frac{1-\sqrt{\left(1-C_{T}\right)}}{2}\left(1+\frac{2 \cdot x}{\sqrt{1+4 \cdot x^{2}}}\right)\right)
$$

With $\mathrm{x}$ : the non-dimensional distance from the auxiliary rotor disk, $\mathrm{Vx}$ the velocity of the disturbed wind between rotors at point $\mathrm{x}$ and $\mathrm{C}_{\mathrm{T}}$ the trust coefficient, which is taken to be 0.9 . So, with respect to $\mathrm{x}=15$, the value of the $\mathrm{Vx}$ close to the main rotor is computable (rotors are located 15 meters apart from each other) [34].

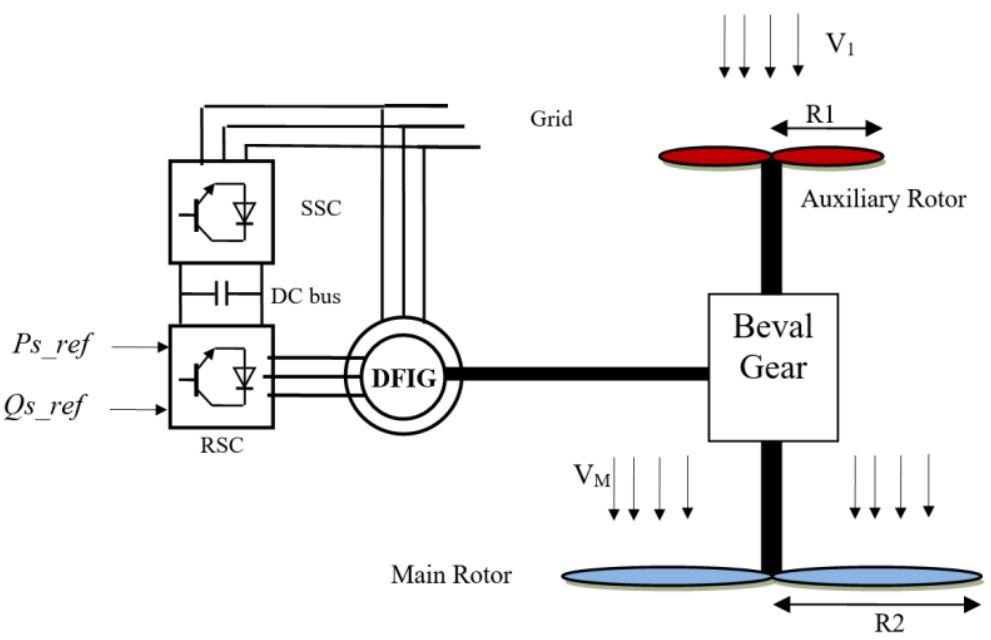

Figure 1. Block diagram of DRWT with a DFIG.

Figures 2-7 show the obtained simulation results. According to these figures, we notice that the mechanical powers extracted are adapted to the variation of the wind speed and the total mechanical power $\left(\mathrm{Pm}_{\mathrm{t}}=0.52 \mathrm{MW}\right)$ at the moment $\mathrm{t}=4 \mathrm{~s}$ is equal to the summation of the two mechanical powers secondary rotor $(\mathrm{Pm} 2=0.02 \mathrm{MW})$ and main rotor $(\mathrm{Pm} 1=0.50 \mathrm{MW})$. 


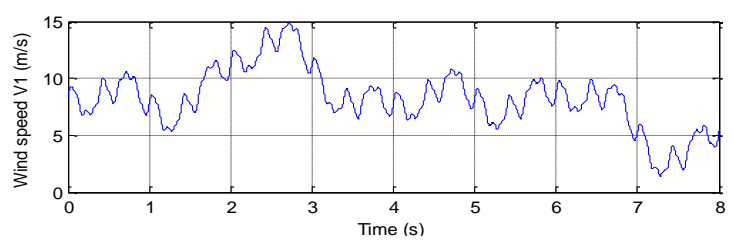

Figure 2. Wind speed V1.

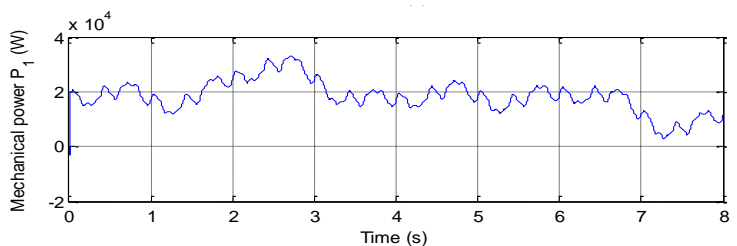

Figure 4. Auxiliary mechanical power.

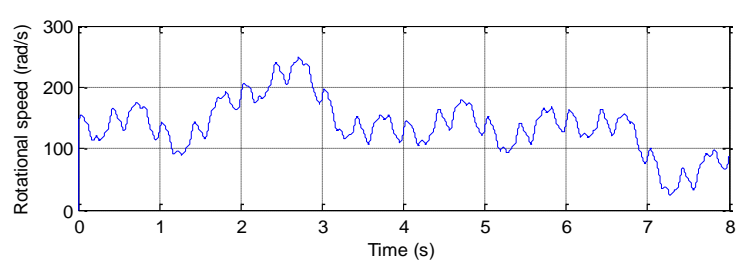

Figure 6. Rotational speed.

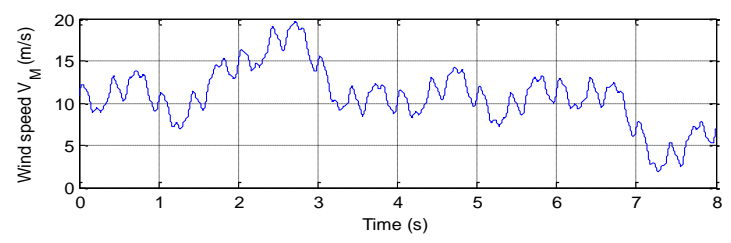

Figure 3. Wind speed $\mathrm{V}_{\mathrm{M}}$.

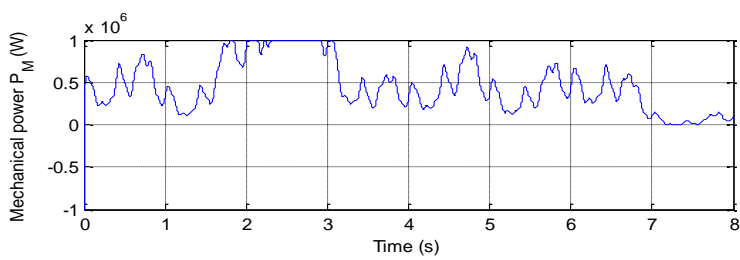

Figure 5. Main mechanical power.

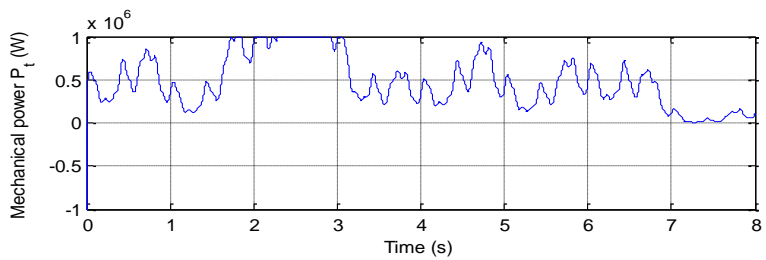

Figure 7. Total mechanical power.

\section{CLASSICAL DPC METHOD}

DPC or direct power command using classical lookup table is the most used command strategy for DFIG-based DRWP systems. In this strategy, two hysteresis comparators are used to controlling the reactive and active powers. However, this method is a simple algorithm and reduced power oscillation, torque oscillation and harmonic distortion (THD) of stator current compared to field-oriented control (FOC). On the other hand, this method gives a fast response dynamic compared to the FOC strategy. Figure 8 shows the classical DPC method of DFIG driven by DRWT.

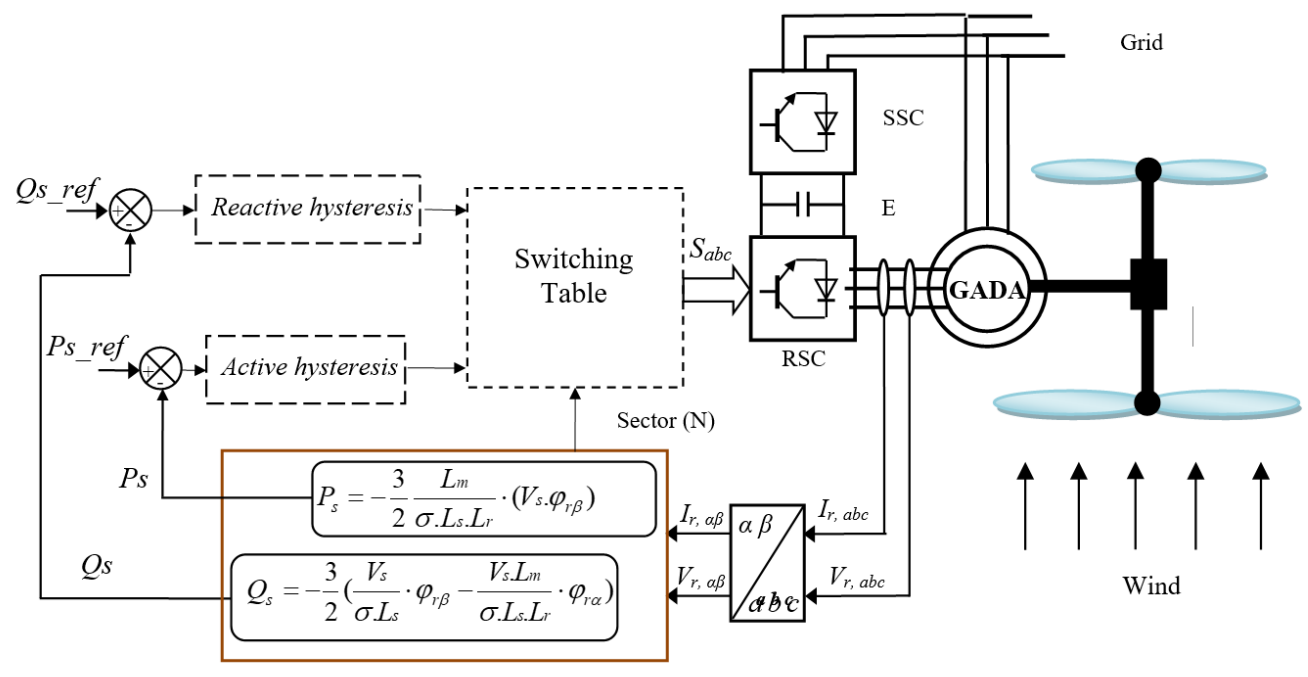

Active, reactive power and sector estimation

Figure 8. Classical DPC control. 
The magnitude of rotor flux, which can be estimated by (12).

$\left\{\begin{array}{l}\emptyset_{r \alpha}=\int_{0}^{t}\left(\boldsymbol{v}_{r \alpha}-R_{r} \cdot i_{r \alpha}\right)^{d t} \\ \emptyset_{r \beta}=\int_{0}^{t}\left(\boldsymbol{v}_{r \beta}-R_{r} \cdot i_{r \beta}\right)^{d t}\end{array}\right.$

The rotor flux amplitude is given by (13) and (14).

$\phi_{r}=\sqrt{\phi_{r \alpha}^{2}+\phi_{r \beta}^{2}}$

And

$$
\left|\overline{\phi_{r}}\right|=\frac{\left|\overline{V_{r}}\right|}{w_{r}}
$$

The rotor flux angle is calculated by (15).

$$
\theta_{r}=\operatorname{arctg}\left(\frac{\phi_{r \beta}}{\phi_{r \alpha}}\right)
$$

Reactive/active power is estimated using (16) and (17).

$$
\begin{aligned}
& P_{s}=-\frac{3}{2} \frac{L_{m}}{\sigma \cdot L_{s} \cdot L_{r}} \cdot\left(V_{s} \cdot \phi_{r \beta}\right) \\
& Q_{s}=-\frac{3}{2}\left(\frac{V_{s}}{\sigma \cdot L_{s}} \cdot \phi_{r \beta}-\frac{V_{s} \cdot L_{m}}{\sigma \cdot L_{s} \cdot L_{r}} \cdot \phi_{r \alpha}\right)
\end{aligned}
$$

Where:

$$
\sigma=1-\frac{M^{2}}{L_{r} L_{S}}
$$

In the classical DPC method, the level of reactive power hysteresis controller is two and the level of active power hysteresis controller is three. Figure 9 represents the reactive hysteresis controller, where this exists as the last output gives the last two values 0 and 1. On the other hand, the output of the active power

\begin{tabular}{|c|c|c|c|c|c|c|c|}
\hline \multicolumn{2}{|c|}{$\mathrm{N}$} & \multirow[t]{2}{*}{1} & \multirow[t]{2}{*}{2} & \multirow[t]{2}{*}{3} & \multirow[t]{2}{*}{4} & \multirow[t]{2}{*}{5} & \multirow[t]{2}{*}{6} \\
\hline $\mathrm{Hq}$ & $\mathrm{Hp}$ & & & & & & \\
\hline \multirow{3}{*}{0} & 1 & 6 & 1 & 2 & 3 & 4 & 5 \\
\hline & 0 & 0 & 7 & 0 & 7 & 0 & 7 \\
\hline & -1 & 2 & 3 & 4 & 5 & 6 & 1 \\
\hline \multirow{3}{*}{1} & 1 & 5 & 6 & 1 & 2 & 3 & 4 \\
\hline & 0 & 7 & 0 & 7 & 0 & 7 & 0 \\
\hline & -1 & 3 & 4 & 5 & 6 & 1 & 2 \\
\hline
\end{tabular}
hysteresis controller is 0,1 and -1 as shown in Figure 10. The output of active and reactive power hysteresis comparators is the input of the switching table. The zone of the rotor flux is six-zone and the lookup table is shown in Table 1.

Table 1. Switching table of DPC method
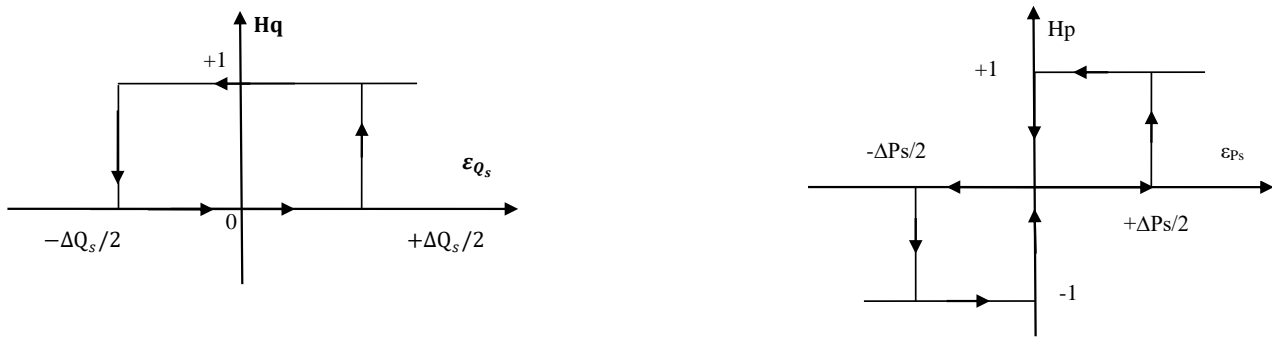

Figure 9. Reactive power hysteresis comparator.

Figure 10. Active power hysteresis comparator. 


\section{DPC-GA METHOD}

In this section, a novel DPC control was designed to regulate torque, active and reactive powers of the DFIG-based DRWT. This designed DPC strategy is based on pulse width modulation (PWM) and genetic algorithm. This proposed DPC method is a simple algorithm, fast response dynamic, robust control compared to classical DPC strategy and vector control. On the other hand, this proposed method reduced the reactive and active power of DFIG-based DRWT. So, the principle of the proposed strategy is a modification of the classical DPC method, where the classical switching table have been replaced by a PWM technique and the two hysteresis comparators of reactive and active powers has been replaced by to genetic algorithm. The proposed DPC strategy, which is designed to regulate the active and reactive powers of the DFIG-based DRWT is shown in Figure 11.

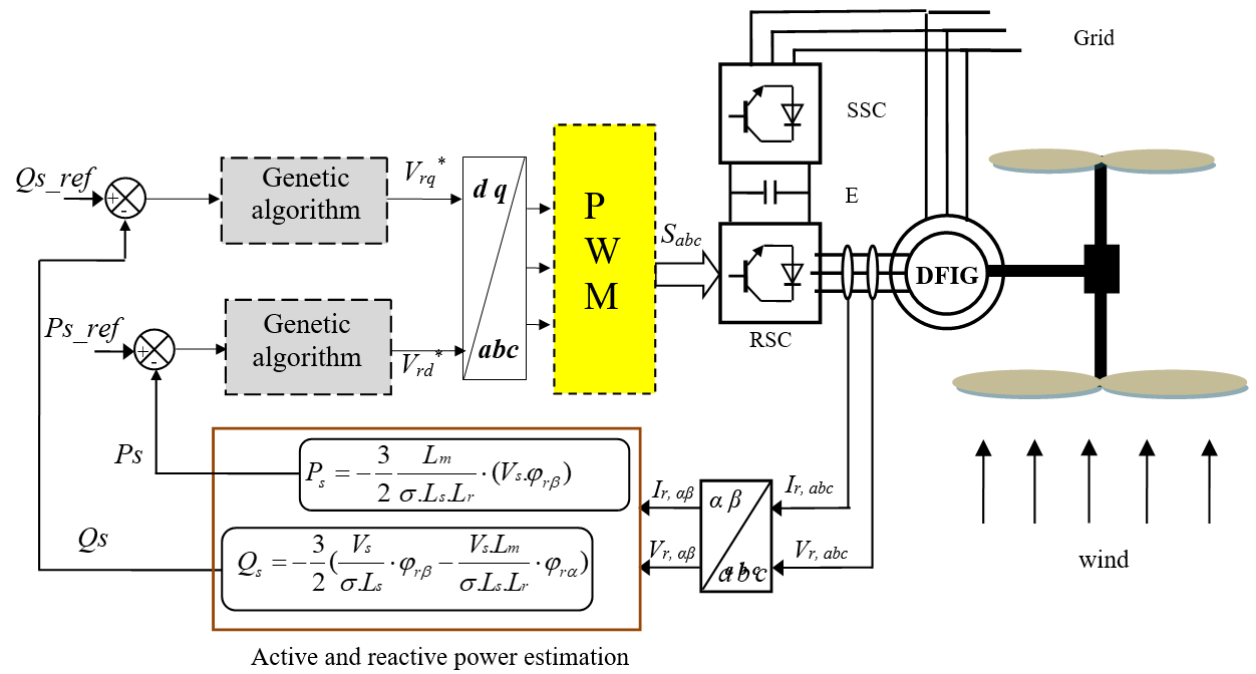

Figure 11. Block diagram DPC-GA of DFIG-based DRWT.

\section{SIMULATION RESULT}

The simulation results of the DPC-GA strategy of a 1.5 MW DFIG are compared with the conventional DPC strategy. The commands system was tested under deferent operating conditions such as a sudden change of load active and reactive powers. The performance analysis is done with torque, THD value of stator current, reactive/active powers. DFIG used for the simulations has the following parameters: $P_{n}=1.5$ MW, $V_{n}=398 \mathrm{~V}, f=50 \mathrm{~Hz}, f_{r}=0.0024 \mathrm{Nm} / \mathrm{s}, L_{s}=0.0137 \mathrm{H}, J=1000 \mathrm{Kg} . \mathrm{m}^{2}, R_{s}=0.012 \Omega, R_{r}=0.021 \Omega, L_{r}=0.0136$ $\mathrm{H}, M=0.0135 \mathrm{H}$ [37], [38]. Table 2 shows parameters of algorithm genetic.

\subsection{Reference tracking test (RTT)}

For the traditional DPC and designed DPC strategy, the reactive power, and active power track well their reference values $\left(P_{\text {sref }}\right.$ and $\left.Q_{\text {sref }}\right)$ as shown in Figures 12 and 13. The active and reactive powers are decoupled from each other in the DPC-GA with a rapid time response, without overshoot, and with a minimal static error compared to the conventional DPC technique. Figure 14 shows the torque of the DPC and DPC-GA strategies. Figure 15 shows the stator current of the designed DPC strategy and the classical DPC. We can see that torque and current of the DFIG are proportional to the variation of reactive/active power reference values. Active power response comparing curves are shown in Figure 16. See figure the active power oscillations are significantly minimized when the DPC-GA strategy is in use. Figure 17 shows the zoom in the reactive power responses of both the DPC technique. It is found that the DPC-GA strategy exhibits smooth response and lesser oscillations in reactive power as compared to the conventional DPC technique.

The DPC-GA technique reduced the torque oscillations compared to the classical DPC technique as shown in Figure 18. From the simulation results presented in Figures 19 and 20, it is apparent that the THD value of stator current for the DPC-GA technique is considerably reduced relative to the classical DPC technique and other strategies as shown in Table 3. Where, DPC-T2FLC is the direct power control with type 2 fuzzy logic controller. DPC-MRAC is the direct power control with model reference adaptive control. FOC is the field-oriented control. DPC-NFC is the direct power control with neuro-fuzzy controller. 
Table 2. Parameters of algorithm genetic

\begin{tabular}{|c|c|c|}
\hline \multicolumn{2}{|l|}{ Current iteration } & 51 \\
\hline \multicolumn{2}{|l|}{ Number of variables } & 3 \\
\hline \multirow[t]{2}{*}{ Bounds lower } & & {$\left[\begin{array}{llll}-10 & -100 & 0\end{array}\right]\left[\begin{array}{lll}200 & 2000 & 0\end{array}\right]$} \\
\hline & Population type & Double vector \\
\hline \multirow[t]{2}{*}{ Population } & Creation function & Use constraint dependant defaut \\
\hline & Population size & Use default: 20 \\
\hline \multicolumn{2}{|c|}{ Fitness scaling: Scaling function } & Rank \\
\hline \multicolumn{2}{|c|}{ Selection: Selection function } & Stochastic uniform \\
\hline \multirow[t]{2}{*}{ Reproduction } & Elite count & Use default: 2 \\
\hline & Cross over fraction & Use default: 0.8 \\
\hline \multicolumn{2}{|c|}{ Mutation: Mutation function } & Use constraint dependent defaut \\
\hline \multicolumn{2}{|c|}{ Crossover: crossover function } & Scattered \\
\hline & Direction & Forward \\
\hline \multirow[t]{2}{*}{ Migration } & Fraction & Use default: 0.2 \\
\hline & Interval & Use default: 20 \\
\hline \multirow[t]{2}{*}{ Algorithm settings } & Intial penalty & Use default: 10 \\
\hline & Penalty factor & Use default: 100 \\
\hline \multicolumn{2}{|c|}{ Hybrid function: hybrid function } & None \\
\hline & Generations & Use default: 100 \\
\hline & Time limit & Use default: inf \\
\hline \multirow[t]{5}{*}{ Stopping criteria } & Fitness limit & Use default: -inf \\
\hline & Stall generations & Use default: 50 \\
\hline & Stall time limit & Use default: inf \\
\hline & Function tolerance & Use default: $1 \mathrm{e}-6$ \\
\hline & Nonlinear constraint tolerance & Use default: $1 \mathrm{e}-6$ \\
\hline \multicolumn{2}{|c|}{ Output function: History to new window } & Interval: 1 \\
\hline \multicolumn{2}{|c|}{ Display to command window } & Level of display: off \\
\hline \multicolumn{2}{|c|}{ User function evaluation } & Evaluate fitness and constraint functions: in serial \\
\hline
\end{tabular}

Table 3. THD value (RTT)

\begin{tabular}{llc}
\hline & \multicolumn{2}{c}{ THD (\%) } \\
\hline & DPC-PI & 2.59 \\
Ref. [39] & DPC-ANN & 1.09 \\
Ref. [40] & DPC-T2FLC & 1.14 \\
& DPC-NFC & 0.78 \\
Ref. [41] & FOC & 3.7 \\
Ref. [42] & SMC & 3.05 \\
& FSMC & 2.85 \\
Ref. [43] & DPC-MRAC & 1.01 \\
Proposed strategy & DPC & 0.54 \\
& DPC-GA & 0.11 \\
\hline
\end{tabular}

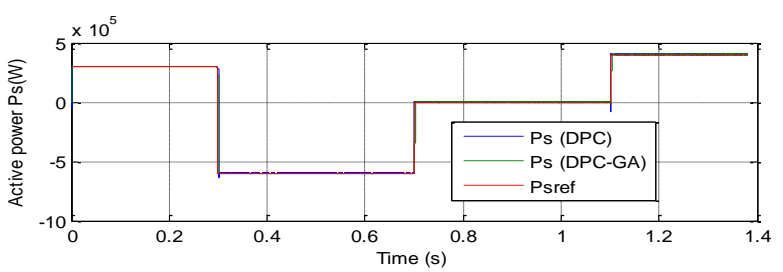

Figure 12. Active power.

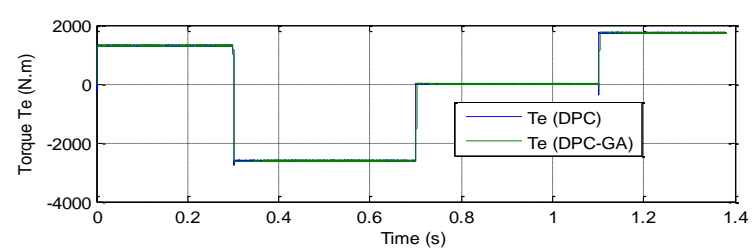

Figure 14. Torque.

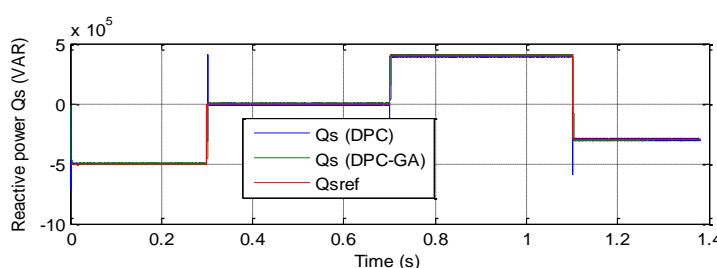

Figure 13. Reactive power.

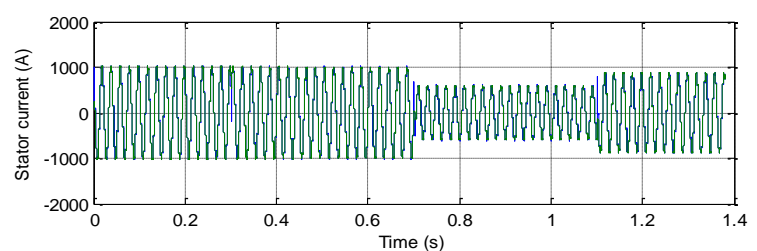

Figure 15. Stator current. 


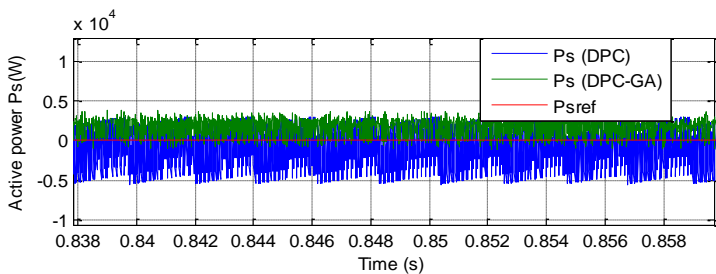

Figure 16. Zoom in the active power

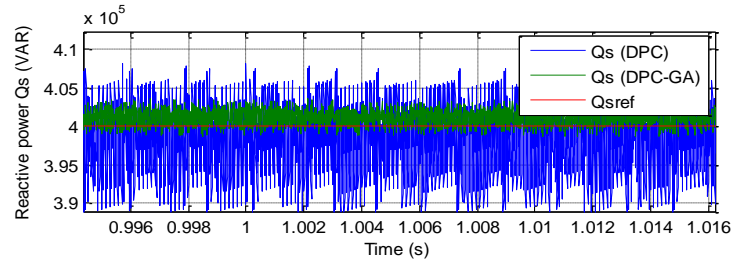

Figure 17. Zoom in the reactive power

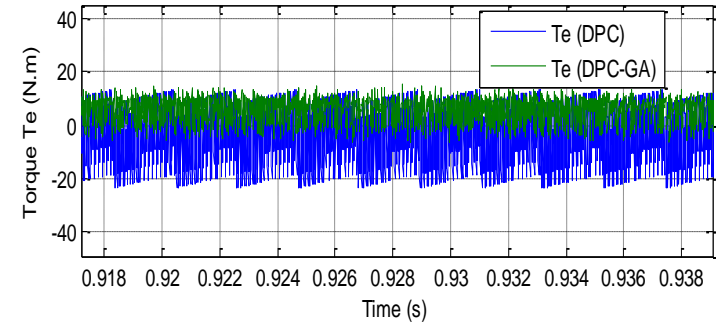

Figure 18. Zoom in the Torque
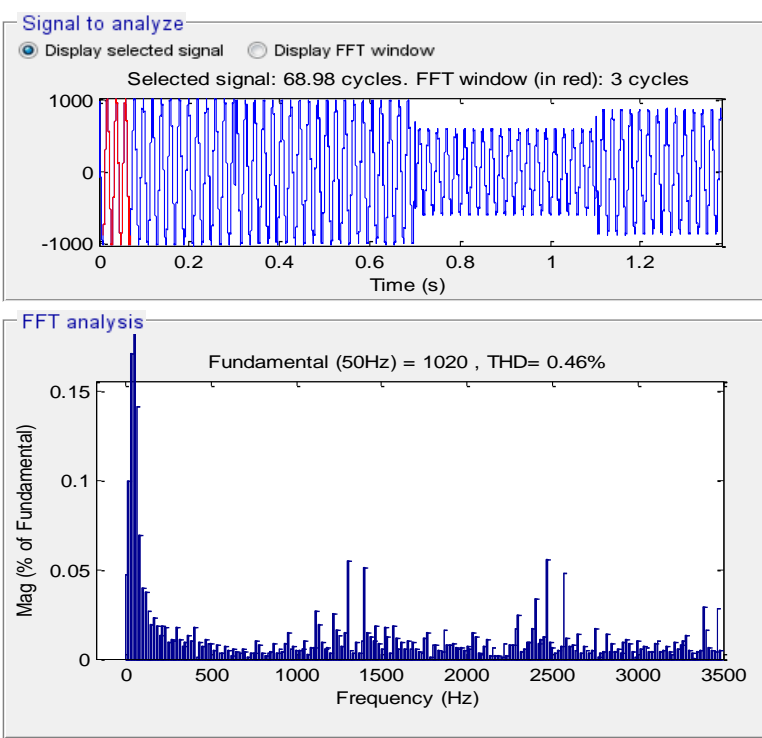

Figure 19. THD value of current (DPC).

Table 4. THD value (RT) THD (\%) DPC DPC-GA

\begin{tabular}{lll}
\hline Stator current & 0.91 & 0.29
\end{tabular}

\subsection{Robustness test (RT)}

In this part, the DFIG parameters have been intentionally changed such as the values of the resistances $R_{s}$ and $R_{r}$ are multiplied by 2 and the values of the inductances $L_{s}$ and $L_{r}$ are multiplied by 0.5 . Simulation results are presented in Figures 21-26. As it's shown by these figures, these variations present a clear effect on reactive power, torque, active power, and current curves and that the effect appears more important for the classical DPC technique than that with designed technique as shown in Figures 27-29. On the other hand, these results show that the THD value of current in the proposed strategy has been reduced significantly as shown in Figures 21-22. Table 4 shows the THD values of both techniques. Thus, it can be concluded that the designed strategy is more robust than the classical DPC technique.
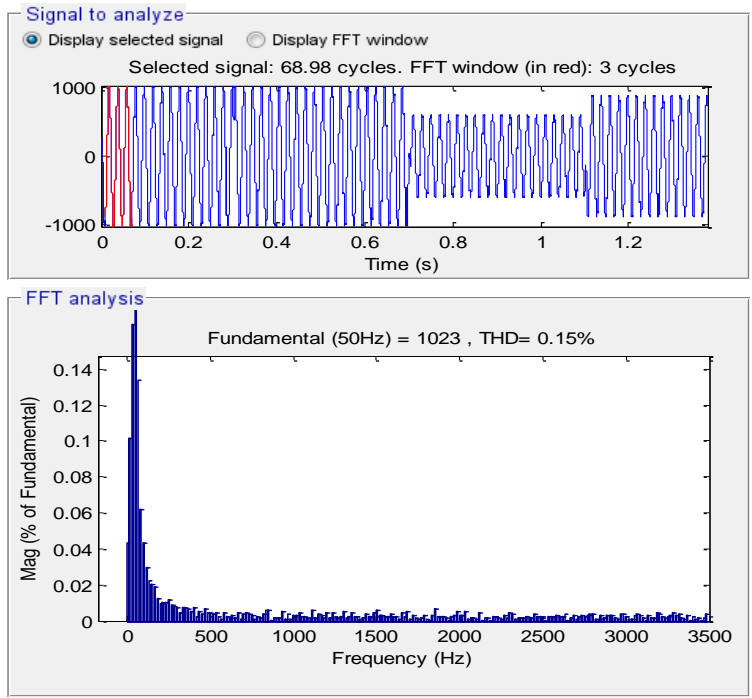

Figure 20. THD value of current (DPC-GA).
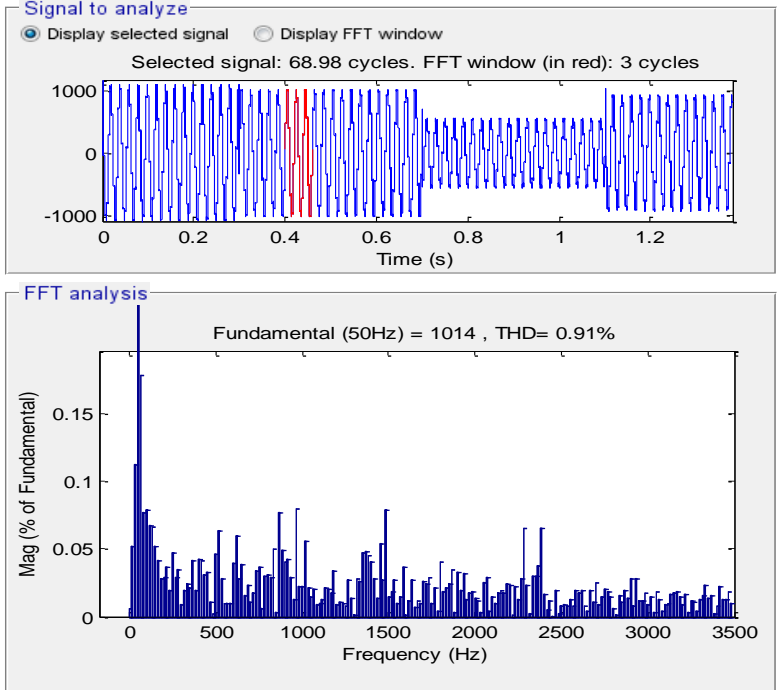

Figure 21. THD value of current (DPC) 

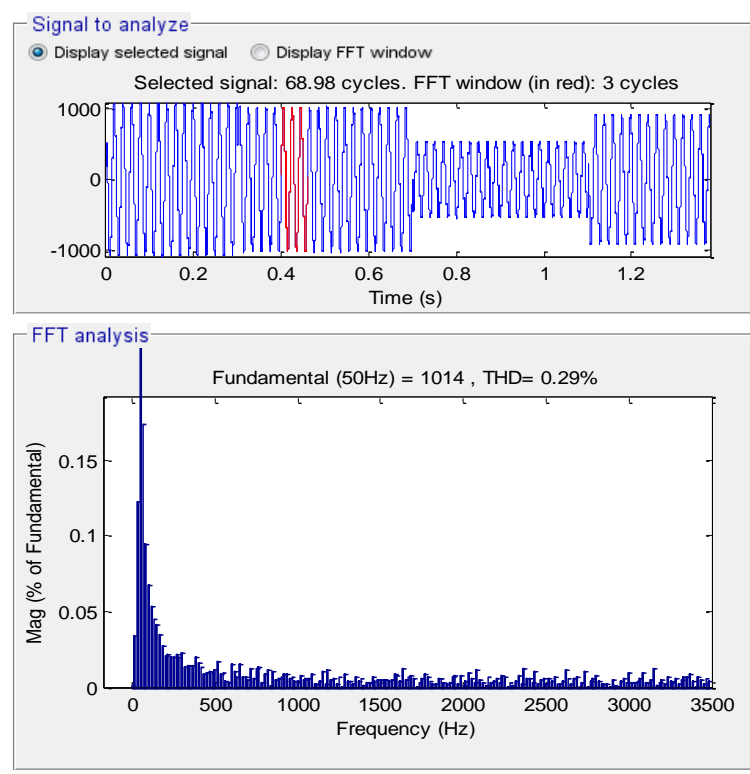

Figure 22. THD value of current (DPC-GA)

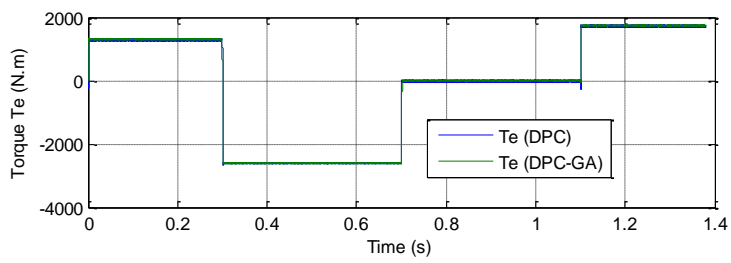

Figure 25. Torque.

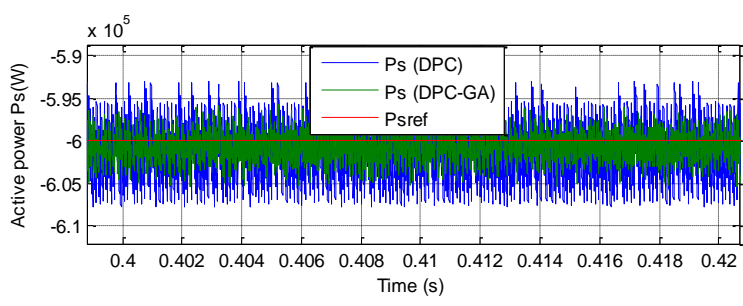

Figure 27. Zoom in the active power.

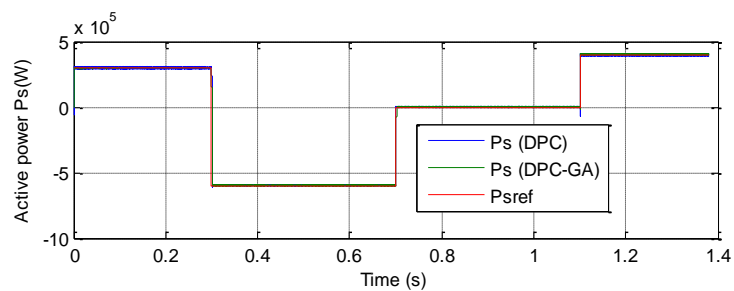

Figure 23. Active power

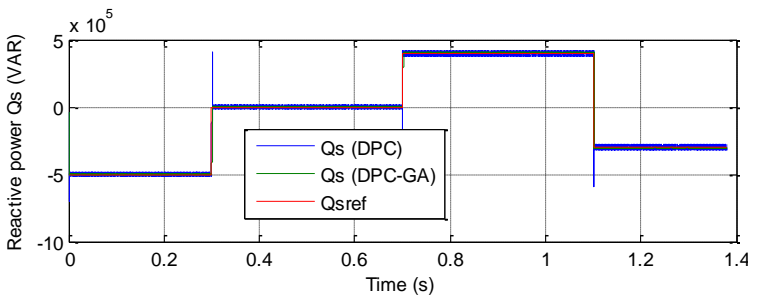

Figure 24. Reactive power.

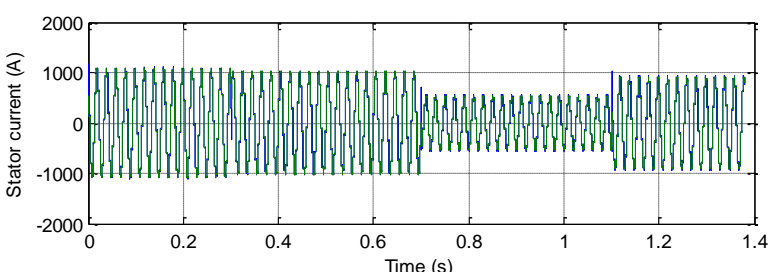

Figure 26. Current.

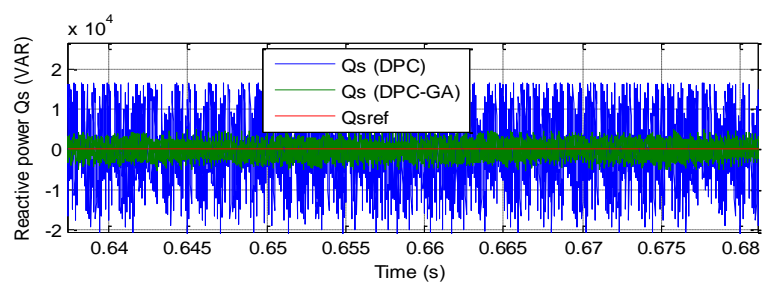

Figure 28. Zoom in the reactive power.

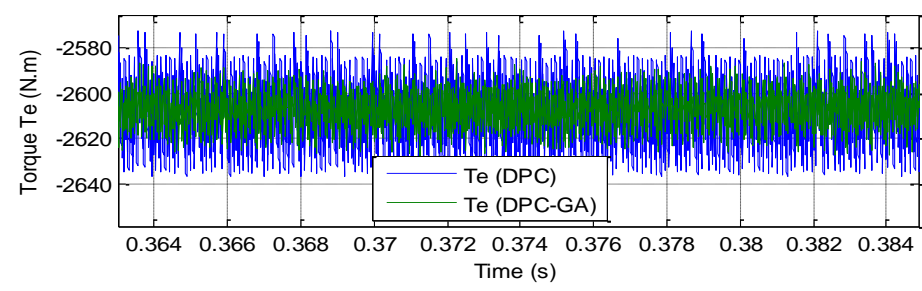

Figure 29. Zoom in the torque.

\section{CONCLUSION}

In order to regulate the active and reactive powers of the DFIG-based DRWP system, a GA method is proposed. The results of simulations have shown that the application of a GA technique gives a good response of reactive and active powers. Power level oscillations are lower relative to classical DPC strategy, 
which is reflected in the quality of the stator currents generated by the DFIG-DRWP. From the comparative study between the designed technique and the classical DPC strategy, it has been shown that the designed GA method is very effective in the stabilization of the system. Therefore, the designed strategy can contribute to expanding wind power utilization.

\section{REFERENCES}

[1] H. Benbouhenni, Z. Boudjema, A. Belaidi, "Using three-level fuzzy space vector modulation method to improve indirect vector control strategy of a DFIG based wind energy conversion systems," International Journal of Smart Grid, vol. 2, no.3, pp.155-171, 2018.

[2] H. Benbouhenni, Z. Boudjema, A. Belaidi, "Indirect vector control of a DFIG supplied by a two-level FSVM inverter for wind turbine system," Majlesi Journal of Electrical Engineering, vol. 13, no. 1, pp. 45-54, 2019.

[3] A. Medjber, A. Moualdia, A. Mellit, M. A. Guessoum,"Comparative study between direct and indirect vector control applied to a wind turbine equipped with a double-fed asynchronous machine Article," International Journal of Renewable Energy Research, vol. 3, no. 1, pp. 88-93, 2013.

[4] N. Khemiri, A. Khedher, M. F. Mimouni, "Wind energy conversion system using DFIG controlled by backstepping and sliding mode strategies," International Journal of Renewable Energy Research, vol. 2, no.3, pp. 422-435, 2012.

[5] Y. Djeriri, "Lyapunov-based robust power controllers for a doubly fed induction generator," Iranian Journal of Electrical and Electronic Engineering, vol. 16, no. 4, pp. 551-558, 2020, doi: 10.22068/IJEEE.16.4.551.

[6] E. M. Youness, D. Aziz, E. G. Abdelaziz, B. Jamal, E. O. Najib, Z. Othmane, M. Khalid, B. Bossoufi, "Implementation and validation of backstepping control for PMSG wind turbine using dSPACE controller board," Energy Reports, vol. 5, pp. 807-821, 2019, doi: 10.1016/j.egyr.2019.06.015.

[7] Z. Boudjema, R. Taleb, A. Yahdou, "A new DTC scheme using second order sliding mode and fuzzy logic of a DFIG for wind turbine system," International Journal of Advanced Computer Science and Application, vol. 7, no. 8, pp. 49-56, 2016, doi: 10.14569/IJACSA.2016.070808.

[8] H. Benbouhenni and Z. Boudjema, "Two-level DTC based on ANN controller of DFIG using 7-level hysteresis command to reduce flux ripple comparing with traditional command," 2018 International Conference on Applied Smart Systems (ICASS), 2018, pp. 1-8, doi: 10.1109/ICASS.2018.8652013

[9] Y. Wa, W.Yang, "Different control strategies on the rotor side converter in DFIG-based wind turbines," Energy Procedia, vol. 100, pp. 551-555, 2016, doi: 10.1016/j.egypro.2016.10.217.

[10] M. S. Raj, T. Saravanan, V. Srinivasan, "A modified direct torque control of induction motor using space vector modulation technique," Middle-East Journal of Scientific Research, vol. 20, no. 11, pp.1572-1574, 2014.

[11] H. Benbouhenni, "Comparative Study between direct vector control and fuzzy sliding mode controller in three-level space vector modulation inverter of reactive and active power command of DFIG-based wind turbine systems," International Journal of Smart Grid, vol. 2, no. 4, pp. 188-196, 2018.

[12] H. Benbouhenni, Z. Boudjema, A. Belaidi, "Direct vector control of a DFIG supplied by an intelligent SVM inverter for wind turbine system," Iranian Journal of Electrical and Electronic Engineering, vol. 15, no. 1, pp. 4555, 2019, doi: 10.22068/IJEEE.15.1.45.

[13] H. Benbouhenni, "Reducing current and torque ripples in DVC control of DFIG operation at constant switching frequency for wind generation application," Majlesi Journal of Energy Management, vol. 8, no. 4, pp. 47-55, 2019.

[14] H. Benbouhenni, Z. Boudjema, A. Belaidi, "DPC based on ANFIS super-twisting sliding mode algorithm of a doubly-fed induction generator for wind energy system," Journal Européen des Systèmes Automatisés, vol. 53, no.1, pp. 69-80, 2020, doi: 10.18280/jesa.530109

[15] K. Boulaam, A. Mekhilef, "Output power control of a variable wind energy conversion system," Rev. Sci. Techni.Electrotechn. Et Energ. vol. 62, no. 2, pp. 197-202, 2017.

[16] M. V. Kazemi, A. S. Yazdankhah, H. M. Kojabadi, "Direct power control of DFIG based on discrete space vector modulation," Renewable Energy, vol. 35, no. 5, pp. 1033-1042, 2010, doi: 10.1016/j.renene.2009.09.008.

[17] A. Izanlo, S. A. Gholamian, M. V. Kazemi, "Comparative study between two sensorless methods for direct power control of doubly fed induction generator," Rev. Roum. Sci. Techn.-Electrotechn. Et Energ, vol. 62, no. 4, pp. 358364, 2017.

[18] J. Hu, J. Zhu, D. G. Dorrell, "Predictive direct power control of doubly fed induction generators under unbalanced grid voltage conditions for power quality improvement," IEEE Transactions on Sustainable Energy, vol. 6, no. 3, 2015, doi: 10.1109/TSTE.2014.2341244.

[19] H. Benbouhenni, "Intelligence indirect vector control of a DFIG based wind turbines," Majlesi Journal of Electrical Engineering, vol. 13, no. 3, pp.27-35, 2019.

[20] H. Benbouhenni, "Robust direct power control of a DFIG fed by a five- level NPC inverter using neural SVPWM technique," TECNICA ITALIANA-Italian Journal of Engineering Science, vol. 65, no. 1, pp. 119-128, 2021. https://doi.org/10.18280/ti-ijes.650118.

[21] H. Benbouhenni, Z. Boudjema, A. Belaidi, "DFIG-based wind energy conversion system using five-level FSVM technique," Int. J. Renewable Energy Technology, vol. 11, no. 2, pp. 147-164, 2020, doi: 10.1504/IJRET.2020.108300.

[22] H. Benbouhenni, Z. Boudjema, A. Belaidi, "DFIG-based wind turbine system using four-level FSVM strategy," Majlesi Journal of Energy Management, vol. 6, no. 3, pp. 7-19, 2017.

[23] T. Gonzales, A. Moreno, L. Fridman, "Variable gain super-twisting sliding mode control," IEEE Transactions on Automatic Control, vol. 57, no. 8, pp. 2100-2105, 2012, doi: 10.1109/TAC.2011.2179878. 
[24] I. Yaichi, A. Semmah, P. Wira, Y. Djeriri, "Super-twisting sliding mode control of a doubly-fed induction generator based on the SVM strategy," Periodica Polytechnica Electrical Engineering and Computer Science, vol. 63, no. 3, pp. 178-190, 2019, doi: 10.3311/PPee.13726.

[25] H. Benbouhenni, Z. Boudjema, A. Belaidi, "Direct power control with NSTSM algorithm for DFIG using SVPWM technique," Iranian Journal of Electrical \& Electronic Engineering, vol. 17, no. 1, pp.1-11, 2021, doi: IJEEE.17.1.1518.

[26] E. G. Shehata, "Sliding mode direct power control of RSC for DFIGs driven by variable speed wind turbines," Alexandria Engineering Journal, vol. 54, no. 4, pp. 1067-1075, 2015, doi: 10.1016/j.aej.2015.06.006.

[27] H. Benbouhenni, "Sliding mode with neural network regulateur for DFIG using two-level NPWM strategy," Iranian Journal of Electrical \& Electronic Engineering, vol. 15, no. 3, pp.411-419, 2019, doi: 10.22068/IJEEE.15.3.411.

[28] S. Tayebi-Haghighi, F. Piltan, J. M. Kim, "Robust composite high-order super-twisting sliding mode control of robot manipulators," Robotics, vol. 7, no. 1, 2018, doi: doi.org/10.3390/robotics7010013.

[29] Y. Guo, H. Long, "Self organizing fuzzy sliding mode controller for the position control of a permanent magnet synchronous motor drive," Ain Shams Engineering Journal, vol. 2, no. 2, pp. 109-118, 2011, doi: 10.1016/j.asej.2011.06.004.

[30] S. Gdaim, A. Mtibaa, and M. F. Mimouni, "Direct torque control of induction machine based on intelligent techniques," International Journal of Computer Applications, vol. 10, no. 8, pp. 29-35, 2010, doi: 10.5120/15002017.

[31] A. Bouyekni, R. Taleb, Z. Boudjema, H. Kahal, "A second-order continuous sliding mode based on DFIG for windturbine-driven DFIG," Elektrotehniški Vestnik, vol. 85, no. 1-2, pp. 29-36, 2018.

[32] S. Massoum, A. Meroufel, A. Massoum, P. Wira, "A direct power control of the doubly-fed induction generator based on the SVM strategy," Elektrotehniski Vestnik/Electrotechnical Review, vol. 84, no.5, pp. 235-240, 2017.

[33] H. Benbouhenni, "ANFIS-sliding mode control of a DFIG supplied by a two-level SVPWM technique for wind energy conversion system," International Journal of Applied Power Engineering, vol. 9, no. 1, pp. 36-47, 2020, doi: 10.11591/ijape.v9.i1.pp36-47.

[34] A. Yahdou, B. Hemici, Z. Boudjema, "Sliding mode control of dual rotor wind turbine system," The Mediterranean Journal of Measurement and Control, vol. 11, no. 2, pp. 412-419, 2015.

[35] A. Yahdou, A. B. Djilali, Z. Boudjema, F. Mehedi, "Improved vector control of a counter-rotating wind turbine system using adaptive backstepping sliding mode," Journal Européen des Systèmes Automatisés, vol. 53, no. 5, pp. 645-651, 2020, doi: 10.18280/jesa.530507.

[36] A. Yahdou, B. Hemici, Z. Boudjema, "Second order sliding mode control of a dual-rotor wind turbine system by employing a matrix converter," Journal of Electrical Engineering, vol. 16, no. 3, pp.1-11, 2016.

[37] H. Benbouhenni, "A comparative study between FSMC and FSOSMC strategy for a DFIG-based wind turbine system," Majlesi Journal of Mechatronic Systems, vol. 8, no. 2, pp. 7-14, 2019.

[38] H. Benbouhenni, "Comparative study between PWM and SVPWM technique for a DFIG-based wind turbine system controlled by fuzzy sliding mode," Majlesi Journal of Energy Management, vol. 7, no. 4, 2018.

[39] H. Benbouhenni, Z. Boudjema, A. Belaidi, "Power ripple reduction of DPC DFIG drive using ANN controller," Acta Electrotechnica et Informatica, vol. 20, no. 1, pp.15-22, 2020, dpoi: 10.15546/aeei-2020-0003.

[40] F. Amrane, A. Chaiba, "A novel direct power control for grid-connected doubly fed induction generator based on hybrid artificial intelligent control with space vector modulation," Rev. Roum. Sci. Tech.-Electrotechn. Et Energ, vol. 61, no.3, pp. 263-268, 2016.

[41] F. Amrane, A. Chaiba, B. Badr Eddine, M. Saad, Design and implementation of high performance field oriented control for grid-connected doubly fed induction generator via hysteresis rotor current controller," Rev. Roum. Sci. Tech.-Electrotechn. Et Energ, vol. 61, no. 4, pp. 319-324, 2016.

[42] Z. Boudjema, A. Meroufel, Y. Djerriri, E. Bounadja, "Fuzzy sliding mode control of a doubly fed induction generator for energy conversion," Carpathian Journal of Electronic and Computer Engineering, vol. 6, no. 2, pp.7$14,2013$.

[43] F. Amrane, A. Chaiba, S. Mekhilef, "High performances of grid-connected DFIG based on direct power control with fixed switching frequency via MPPT strategy using MRAC and neuro-fuzzy control," Journal of Power Technologies, vol. 96, no.1, pp. 27-39, 2016, doi: 0000-0001-9265-4412.

\section{BIOGRAPHIES OF AUTHORS}

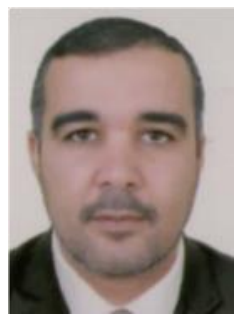

H. Benbouhenni was born in chlef, Algeria. He is a $\mathrm{PhD}$ student in the Departement of Electrical Engineering, ENPO-MA, Oran, Algeria. He received M.A. degree of automatic and informatique industrial in 2017. His research activities include the application of robust control in the wind turbine power systems. E-mail: habib_benbouhenni@yahoo.com 